\title{
Development of Inventory Management Application Using Points Of Sale laravel
}

\author{
Hanafi Kambivi \\ State Agricultural Polytechnic \\ Samarinda \\ Software Engineering Technology, \\ Agricultural Management \\ Samarinda, Indonesia \\ hanafikambivi1200@gmail.com
}

\author{
Eko Junirianto \\ State Agricultural Polytechnic \\ Samarinda \\ Software Engineering Technology, \\ Agricultural Management \\ Samarinda, Indonesia \\ eko.ilkom@gmail.com
}

\author{
Nisa Rizqiyah Fadhliyah \\ State Agricultural Polytechnic \\ Samarinda \\ Software Engineering Technology, \\ Agricultural Management \\ Samarinda, Indonesia \\ nisarizqiyah@gmail.com
}

\begin{abstract}
-development of the business world encourages companies to always try to improve the quality of products and services to consumers. The implementation of Reviews These solutions business is a commitment in increasing the competitive advantage of corporate customers in terms of efficiency, effectiveness, performance, and business development. The purpose of this research is to conduct an analysis and design of a point of sale (POS) management application to support the purchasing service system and a stock of goods that can help small and medium entrepreneurs in the data management. The making of this POS application starts from the collecting all the data needed using observation and interview methods, designing an application models with an object-based approach diagram with application design tools in the form of a flowchart and Unified Modeling Language (UML) until the implementation of this POS application. With the application of the point of sales (POS) application can help the tasks of all stakeholders or related parties directly related to the POS application.
\end{abstract}

Keywords: Stock management, point of sales, laravel, Unified Modeling Language

\section{I.INTRODUCTION}

Inventory is operational problems often faced by supermarkets. Inventory can be a number of items placed in the window of the supermarket or could be the number of goods stored in the warehouse. If the amount is too little inventory and demand can not be met due to lack of supplies, it will cause consumers to be disappointed and there is the likelihood that consumers will not go back again. Similarly, if inventory is too large, it will result in losses for the supermarket because they have to provide a larger venue, the possibility of depreciation of value to the goods, as well as the need to provide any additional expenses related to inventory costs such as maintenance costs and cost accounting. Therefore, Management should be able to decide how much of an item to be prepared (distock) for the purposes of self-service. In addition, management should also be cautious in view the needs of consumers so that they feel satisfied because getting what they need.

To see and get the right amount of inventory and can see the needs of consumers, management must often conduct studies on the issue. They require market surveys, analyzing sales data, observing buying patterns, observing the relationship of goods purchased by consumers, and others activities. One study that can be done to determine the condition of the market (consumers) is to observe a sales transaction and continued with the processing of the sales data. With the processing of the sales data, the management can get information that is used for inventory management purposes such as determining the number of self-service items must be prepared in the warehouse, set the minimum amount of stock and maximum stock levels for each item. In addition, by using this information, management can decide when they need to re-order purchase of goods at the supplier, determine the strategies that must be done if the goods are moving stock slow and determine what items should be removed from the stock because it is not in demand by consumers. From the processing of this data can also be obtained linkages between the goods purchased by consumers. Information about the relationship of this stuff can be used to determine marketing strategies and improve service to consumers From the processing of this data can also be obtained linkages between the goods purchased by consumers. Information about the relationship of this stuff can be used to determine marketing strategies and improve service to consumers From the processing of this data can also be obtained linkages between the goods purchased by consumers. Information about the relationship of this stuff can be used to determine marketing strategies and improve service to consumers(Gaffar, 2013)

Based on the above description of the background can be formulated existing problems such as how to develop WEB POS applications, and can monitor sales and stock reports.

So that more targeted research conducted in accordance with the purpose of research, then made the problem definition. This application for managing purchases, purchase report management and inventory management.

The objectives and expected results of the study include:

to facilitate the control stock of products and purchases with smartphones via Website.Bisa synchronize online databases with web service.

\section{LITERATURE REVIEW}

\section{A. Scientific studies}

Some of the literature used as guidelines for the manufacture of this thesis is as follows:

Research conducted by (Surya, Salim, \& Davin, nd)entitled System Application WEB-Based Point Of Sales At PT. Digital System Technology. This study aimed to analyze the problems arising from the existing system at PT. Digital System Technology. Improve the performance of companies in the processing of data for inventory becomes more regular. Evaluating the results of the design and improve the performance of the company.

Research diilakukuan by (Yulianty, 2010) title Applications Point Of Sales In Retail Company (Case Study: Company Artha Jaya, Banjarnegara)This is aimed at the development of applications Point of Sale (POS) in retail stores integrated 
data warehousing of goods on the system, making use of barcode scanning feature on the web-based POS applications. Creating a transaction logging feature, journals, ledgers, and sales reports and inventory reports on retail stores.

Research conducted by (Dalgleish et al., 2007)titled making the application of point of sale in cv. The media wacky aims to design and build a point of sales (POS) standards in accordance with the needs of CV Wacky Media, and become tools for the marketing for the promotion of products $\mathrm{CV}$ Wacky Media.

Research conducted by Nur Heri (Cahyana, Yuwono, \& Asmoro, 2012)entitled Development of Information Systems Web-Based Inventory at PT. Agung Putra Setia. This facilitates the management of the company to obtain information about about reports that are stored in a database processing of inventory from ordering goods to the production process. The system is intended in staff management, especially on the production manager. Inventory control and processes so that the production of goods can be properly controlled.

Research done by (Herman et al., 2016)entitled Making Applications Point of Sales for Eating Kitchen Rinjani. This made the application can display the order, displays the number of stock items that can be ordered, displaying the reservation, featuring sales and stock reports, do the replacement status of orders in the kitchen, and to update the data item, and the item category. Applications can run all the features available through a local network connection and questionnaire Based on the results obtained to assist in the restaurant, $40 \%$ of respondents answered well, and $60 \%$ of respondents answered sufficiently. This indicates that the application can help the process of home dining. Based on the results of questionnaires were obtained for interface design of applications, $20 \%$ of respondents answered less, $60 \%$ of respondents answered sufficiently, and $20 \%$ responded well.

Research done by the very important role of information technology in various agencies. Koperasi Bina Kasih Sejahtera University of Dhyana Pura is a cooperative which has two business areas, namely trade and savings and loan business. However, there are some problems encountered in sales activities, procurement and reporting. The problem occurs in the recording process is still done by hand. So often spend a lot of books every time there is a transaction and less accuracy in data collection and procurement transactions, and transaction data items are not accurate and have an impact on this keuntungan.Penelitian reporting process using several methods including, descriptive methods used in data collection well in literature and field studies. Waterfall method is used to analyze and design applications where the stages take the basic activities that are used in almost all software development data card, so it can be easier to understand. FIFO (First In First Out)implemented in the reporting process in this research is the application aplikasi.Hasil Point Of Sale (POS) Using Barcode Koperasi Bina Kasih Sejahtera On Desktop-Based Methods First In First Out (FIFO), making it easier for administrators or officers in serving the consumer in terms of trade.

Based on research done previously, the research titled Application Development Inventory Management Point Of Sale By Using this laravel will be created with the Web-based to be an Android-based applications with laravel as a framework.
Table 1, List of Scientific Studies

\begin{tabular}{|c|c|c|c|}
\hline No. & Name & Title & Year \\
\hline 1 & Surya et al & $\begin{array}{c}\text { System Application } \\
\text { WEB-Based Point }\end{array}$ & 2013 \\
\hline 2 & Yulianty & $\begin{array}{l}\text { Of Sales At PT. } \\
\text { Digital System } \\
\text { Technology } \\
\text { Applications Point } \\
\text { Of Sales In Retail } \\
\text { Company (Artha } \\
\text { Jaya Company Case }\end{array}$ & 2012 \\
\hline 3 & Cahyana et al & $\begin{array}{c}\text { Study, } \\
\text { Banjarnegara) } \\
\text { Development of } \\
\text { Information } \\
\text { Systems Web- }\end{array}$ & 2012 \\
\hline 4 & Herman et al & $\begin{array}{l}\text { Based Inventory at } \\
\text { PT. Agung Putra } \\
\text { Setia } \\
\text { Making the Point of } \\
\text { Sales Application } \\
\text { for Eating Kitchen } \\
\text { Rinjani }\end{array}$ & 2016 \\
\hline
\end{tabular}

\section{B. Theory Analysis and Design System}

Systems analysis phase conducted after the planning phase systems (systems planing) and before the stage of system design (systems design). The analysis system can be defined as the decomposition of a complete information system in its component parts with a view to identify and evaluate the problems, opportunities, barriers that occur and needs expected that the amendments can be proposed(Hartono, 2005),

1. Detection problems (Problem Detection).

2. Research / investigation beginning (Initial Investigation).

3. Analysis of system requirements (Requirement Analiyis).

4. Sorting system requirements (Generation of System Alternatives).

5. Choosing a good system (Selection of Proper System).

\section{UML (Unified Modeling System)}

UML is a language used to visualize, construct, and document an information item. UML offers a standard for modeling a system. By using UML we can create a model for all types of software applications, where the application can run on any hardware, operating system and any network, and written in any programming language. Other languages such as UML defines notations and syntax / semantics. UML notation is a set of special forms to describe various software diagrams. Each form has a specific meaning, and UML syntax defines how these forms can be combined. UML notation is mainly derived from the 3 notation that has gone before: Grady Booch OOD (Object Oriented Design), Jim Rumbaugh OMT (Object Modeling Technique), and Ivar Jacobson OOSE (Object Oriented Software Engineering). Unified Modeling Languange has several types of diagrams. 
Here is a division of UML diagram types(Dharwiyanti \& Wahono, 2003),

\section{Use Case Diagram}

Use case diagrams describe the functionality expected of a system. The emphasis is "what" is done the system, and not the "how". A use case represents an interaction between the actors in the system. Use case is a specific job, such as login to the system, aligning create a shopping list, and so can be seen in Figure 1. Example Usecase Diagram. An actor is a human entity or machine that interacts with the system to perform certain jobs(Dharwiyanti \& Wahono, 2003),

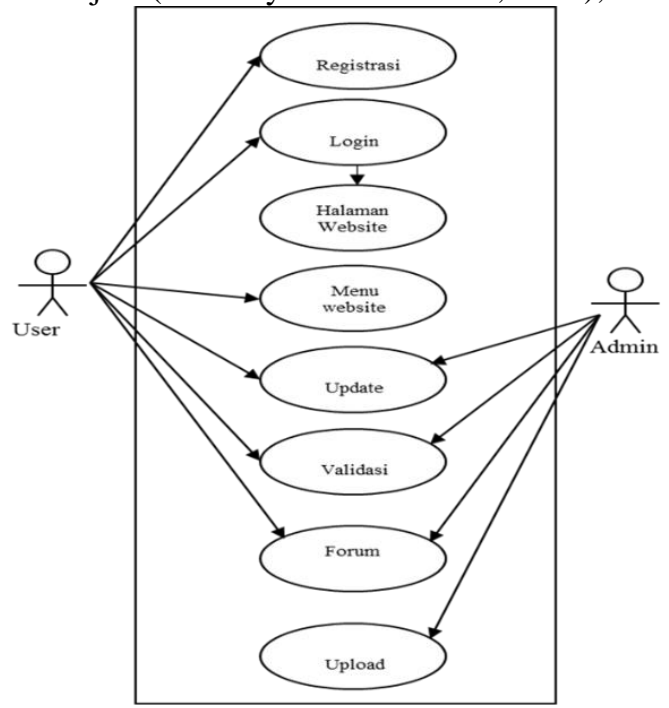

Picture 1, Diagram usecase(Dharwiyanti \& Wahono, 2003)

\section{Class Diagram}

Class is a specification that if diinstansiasi will produce an object and is the core of development and object-oriented design. Class describes the state (attribute / property) system, while offering services to manipulate the situation (method / function). Class diagram describing the structure and description of classes, objects and their package and relationship to one another such as containment, inheritance, associations, and others can be seen in Figure 2. Example Class Diagram. Class has three principal areas, namely the names, attributes and methods.

Attributes and methods can have one of the following properties:

1. Private, can not be called from outside the class in question.

2. protected, Can only be invoked by the relevant class and children who inherit it.

3. public, Can be called by anyone.

Class can be an implementation of an interface, which is an abstract class that only has methods. Interface can not be directly diinstansikan, but must be implemented first into a class. Thus the interface supports the resolution of the method at runtime.

Relationships Class:

1. Association, the static relationships between classes. Generally describes the classes that have attributes such other class or classes to know the existence of another class. Navigability arrows indicate the direction of queries between classes.
2. Aggregation, namely the relationship which declared section ( "made up ...").

3. Inheritance, namely the hierarchical relationship between classes. Class can be derived from another class and inherits all the attributes and methods of class origin and adding new functionality, so she called the son of the inherited class. The opposite of inheritance is a generalization.

Dynamic relationship, which is a series of messages (message) that is passed from one class to another class. Dynamic relationship can be described using sequence diagrams which will be described later(Dharwiyanti \& Wahono, 2003),

\begin{tabular}{|c|c|}
\hline Buku Tamu & Artikel \\
\hline$\langle<\mathrm{PK}>>$ idbukutamu:int & \multirow{6}{*}{$\begin{array}{l}\text { Anker } \\
<\text { PK }>>\text { idartikel:int } \\
\text { artanggal :string } \\
\text { arhari istring } \\
\text { arkategori :string } \\
\text { arpenulis :string } \\
\text { arjudul:string } \\
\text { arheader:string }\end{array}$} \\
\hline Tanggal:string & \\
\hline Nama :string & \\
\hline Email :string & \\
\hline & \\
\hline \multirow{6}{*}{$\begin{array}{l}<\text { PK >>idkomentar:int } \\
\text { kotanggal :string } \\
\text { kohari :string } \\
\text { konamauser:string } \\
\text { kopesan:string }\end{array}$} & \\
\hline & \\
\hline & \\
\hline & \multirow{3}{*}{$\begin{array}{l}\text { Admin } \\
<<\text { PK }>>\text { idadmin:int } \\
\text { namauser string } \\
\text { Password :string }\end{array}$} \\
\hline & \\
\hline & \\
\hline \multicolumn{2}{|l|}{ Kegiatan } \\
\hline$<<$ PK $>>$ idkegiatan:int & \multirow{11}{*}{$\begin{array}{l}\text { Anggota } \\
<<\text { PK>>idanggotaint } \\
\text { tanggal :string } \\
\text { namauser :string } \\
\text { password :string } \\
\text { nama:string } \\
\text { jeniskelaminin:string } \\
\text { alamat:string } \\
\text { kota:string } \\
\text { pekerjaan:string } \\
\text { email:string } \\
\text { telepon:string } \\
\text { hp:string }\end{array}$} \\
\hline ketanggal string & \\
\hline kehari 'string & \\
\hline kenama:string & \\
\hline keheader:string & \\
\hline keisi:string & \\
\hline Forum & \\
\hline$<<\mathrm{PK}>>$ idforum:int & \\
\hline fotanggal :string & \\
\hline fohari :string & \\
\hline $\begin{array}{l}\text { fonamauser:string } \\
\text { fokategori :string }\end{array}$ & \\
\hline fotopik:string & \\
\hline
\end{tabular}

Picture 2, Class Diagram(Dharwiyanti \& Wahono, 2003)

\section{3. statechart Diagram}

statechart diagram describes the transition and changes in circumstances (from one state to another) of an object on the system as a result of stimuli received. In general statechart diagram describing a particular class (a class can have more than one statechart diagram). In UML, state described rectangular with rounded corners and has the appropriate name of the current condition. Transitions between states generally have a guard condition that is necessary for a transition in question, written in brackets. Action carried out as a result of specific events written by starting a slash. Start and end point described a circle full colored and colorless half. Can be seen in Figure 3. Example Statechart Diagram(Dharwiyanti \& Wahono, 2003),

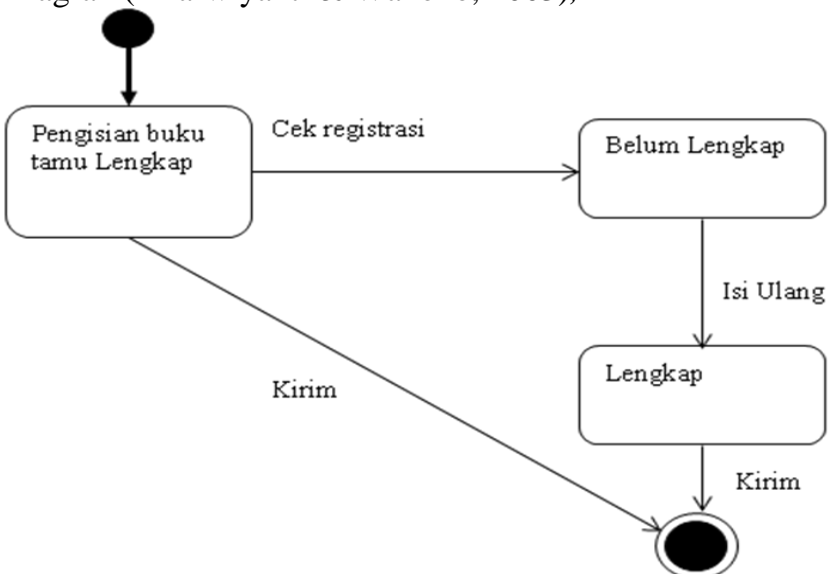

Picture 3, statechart Diagram(Dharwiyanti \& Wahono, 2003) 


\section{Activity Diagram}

Activity diagram describe a variety of flow of activity in the system that is being designed, how each flow starts, decision that might occur, and how they ended. Activity diagrams can also describe parallel processes that may occur in several executions. Activity diagram is a special state diagram, where most of the action and the state is largely a transition triggered by the completion of the previous state (internal processing). Therefore, activity diagrams do not depict the internal behavior of a system and the interaction between subsystems are inexact, but rather describe the processes and pathways of activity above the general level.

Just like the state, using the UML standard rectangular with rounded corners to describe the activity. Decision is used to describe the behavior in certain circumstances, is depicted with a symbol of a rhombus. To illustrate the parallel processes (fork and join) used synchronization point can be the point, horizontal or vertical lines. Activity diagrams can be divided into several objects swimlane to describe the object which is responsible for a particular activity(Dharwiyanti \& Wahono, 2003), For example acitivity diagram is shown in Figure 4. Example Activity Diagram below.

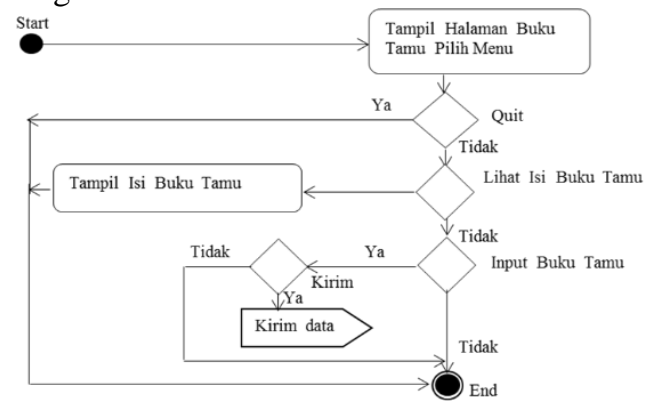

Picture 4, Activity Diagram(Dharwiyanti \& Wahono, 2003)

\section{5. sequence Diagram}

sequence diagrams describe interactions between objects in and around the system (including users, displays, and so on) in the form of message that is described with respect to time. Sequence diagrams consist inter vertical dimension (time) and horizontal dimension (related objects). Sequence diagrams used to describe a scenario or series of steps taken in response of an event to generate a specific output. Starting from what is triggering these activities, processes and any changes that occur internally and what the resulting output. Each of these objects, including actors, has a vertical lifeline. Message depicted as a line-Arrow from one object to another. In the next design phase, the message will be placed into operation / method of the class. Activation bar indicates the length of the execution of a process, usually starting with the receipt of a message. For objects that have special properties, the UML standard defines a special icon for the object boundary, controller and persistent entity(Dharwiyanti \& Wahono, 2003), Overview groove Sequence Diagram can be seen in the illustration Figure 5. Example Sequence Diagram below:

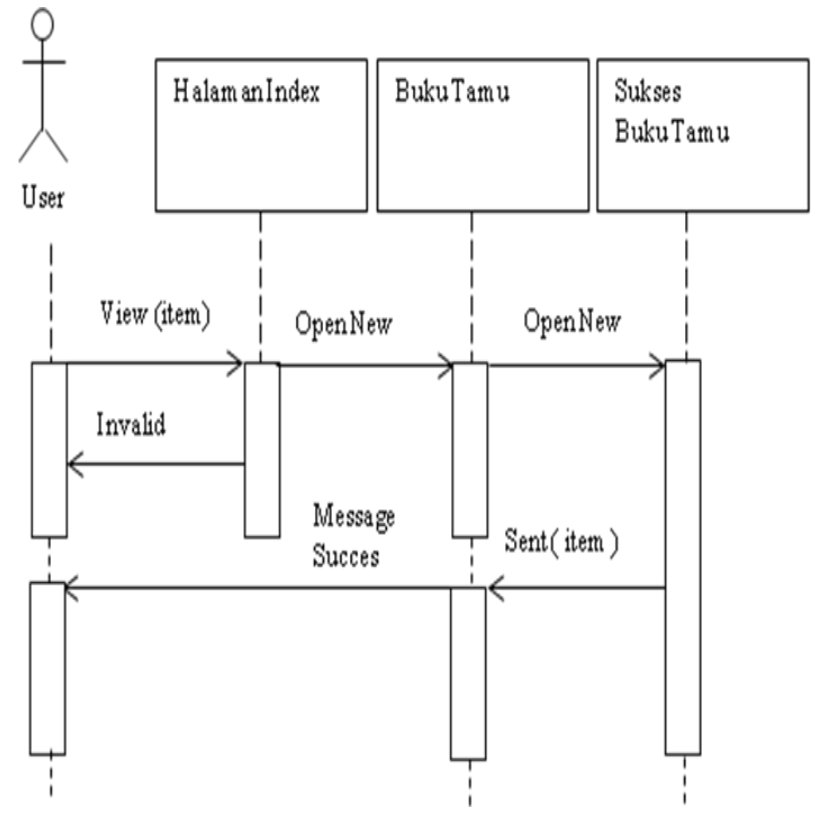

Picture 5, sequence Diagram(Dharwiyanti \& Wahono, 2003)

\section{Collaboration Diagram}

Collaboration Diagramalso describe the interactions between objects such as sequence diagrams, but more emphasis on the role of each object and not at the time of delivery of the message. Each message has a sequence number, in which the message of the highest level has the number 1 (one). Messages of the same level have the same prefix as well.

\section{Component Diagram}

Component Diagramdescribe the structure and relationships between software components, including dependence (dependency) between them. Components of the software is a module containing the code, both contain source code or binary code, both libraries and executables, both of which appear at compile-time, link-time, and run time(Dharwiyanti \& Wahono, 2003), Can be seen in Figure 6. Example Component Diagram. 


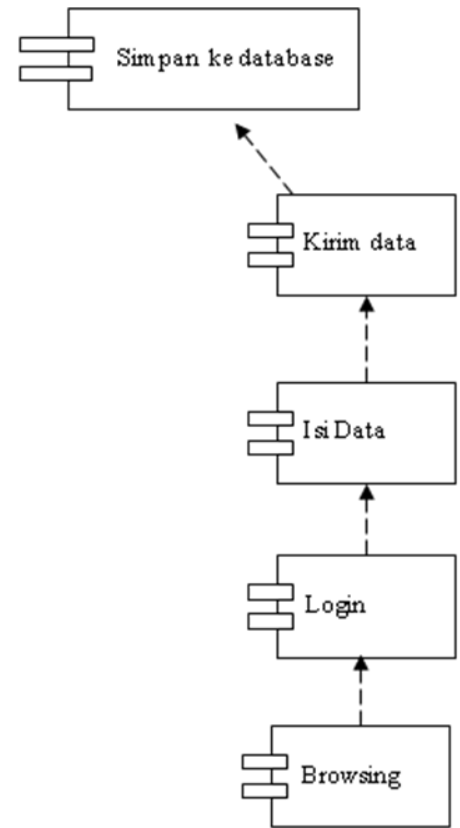

Picture 6, Component Diagram(Dharwiyanti \& Wahono, 2003)

Generally, the components are formed of some class or package, but also of the components are smaller. Components can also be an interface, which is a collection service provided a component to another component.

\section{8. deployment Diagram}

Deployment / physical diagram describe in detail how the components deployed in the infrastructure system, in which the components will be located (on the machine, the server hardware or anything), how the network capabilities in that location, server specifications, and other things that are physical. A node is a server, workstation or other hardware device that is used to deploy the components in the actual environment(Ading, 2013),

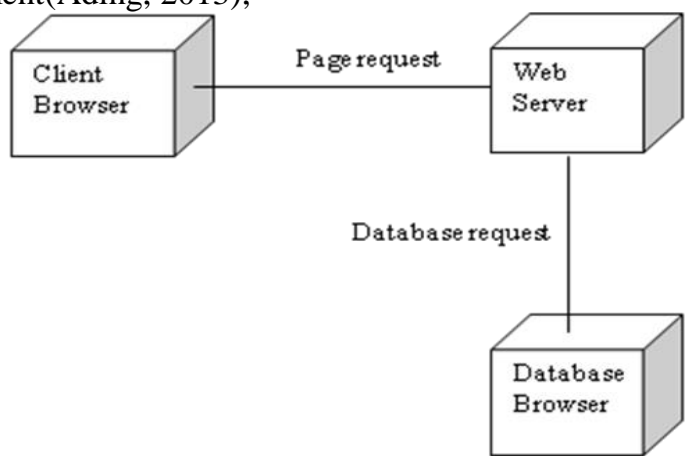

Picture 7, deployment Diagram(Ading, 2013)

\section{Framework laravel}

Laravel is a PHP framework that emphasizes simplicity and flexibility in design. Laravel released under the MIT license with source code provided at Github. Just like other PHP framework, built on the basis laravel MVC (ModelViewController). Laravel equipped ynag command line tool called "Artisan" which can be used for packaging and installation bundle bundle. Framework laravel made by Taylor Otwell, laravel project started in April 2011. The beginning of this project was made because Otwell itself does not find a framework that is up-to-date with the version of
PHP. Framewrok develop existing ones is also not a good idea because of limited resources. Due to some limitations, Otwell create your own framework with laravel name. Therefore laravel menisyaratkan PHP version 5.(Rohman, 2014)

\section{E. PHP (Hypertext Preprocessor)}

PHP is a programming language that allows web developers to create dynamic web applications quickly and easily. PHP pioneered and introduced the first time around 1994 by Rasmus Lerdorf through its website to find out who has access to her online summary.

PHP is a server-side language scipting that can be integrated with HTML tags. Server-side scipting is the syntax and commands that are executed on the server and in included in the HTML document. On a dynamic web pages, PHP serves as the programming language to run a specific command, while HTML serves as the structure of web page design. When a dynamic web page opened in a web page browser, the first time that happens is that the server processes all orders existing PHP and displays the results in HTML format to the web browser, so the show to a web browser only see the design of HTML, while the PHP script working behind the scenes. PHP is open source software, so PHP can be used by anyone for free without having to pay.(Ading, 2013),

F. Web Service

Web Service is a form of development of today's technology that can be used for system integration. The real form of Web Service development today is the presence of WS-based RESTful. RESTful WS Meng found very good in optimizing work(J, S, and Yan, 2009), When the WS RESTful server accessible on a large scale and simultaneously in a distributed system on the internet, because it has a stable and high performance. However, the security RESTful is one of the important points that must be considered.

The main idea of REST is the concept of resource as a component of the application that need to be used or addressed. REST WAS build integrase in a way that is lighter and simpler, and focuses on resources. REST can be described in five boundaries, including:

1. Resource Identification: Web relies on a Uniform Resource Identifier URI) to identify the resources, so that links to resources can be established using identification scheme that is easy to recognize.

2. connectedness: Means that clients of RESTful Service should follow the links to find the resources to be able to interact with the Service.

3. Uniform Interface: Means that resources must field is available through a unified interface that defines the semantics of interaction, such as Hypertext Transfer Protocol (HTTP). HTTP includes methods POST, GET, PUT and DELETE.

4. self-Describing Messages: means to expose the existing resources, restful use one data format (XML, JSON, $\mathrm{RDF}$, etc.) compared to SOAP (XML), but this depends on the developer.

5. stateless Interactions: Require that any request from the client a complete, in the sense that all of the information to serve a request to the server must contain all 
information necessary for the request can be understood, and there is no dependence on state or a sign of a client.

There are two parts of the messages used to establish communication with the server, a message header and message body. HTTP header, which generally include request headers, response headers, and there is an entityheader field. Each request resources from each client can be controlled by using the HTTP Header. Each column header consists of a name followed by a colon ( ":") or white space and content fields. The field name is case-sensitive. The header contains all the information necessary to collect the request and response methods(Tanaem, 2016)

H. MySQL DataBase

Base (database) is a mechanism used to store information or data. With the database, users can store data in an organized manner. Once the data is stored, the information should be easily retrieved. The criteria can be used to retrieve information. How data is stored in a database determines how easily search for information based on many criteria. Data were easily added to the data base, modified, and deleted. MySQL is one type of database server that is widely used and very popular. Its popularity is due to MySQL using SQL as the basic language to access the database. MySQL is free (no need to pay to use it). With MySQL, we can create a centralized database, and separates between application programs to the database,(Utami, 2015)

\section{RESEARCH METHODS}

\section{A. Place and time}

This research was conducted in the area of Jalan Kapten Soedjono.Aj, Cafe Pick Red as research objects. Creation and development of the system is done in Jalan Samratulangi, Agricultural Polytechnic Samarinda. The study was conducted for 6 months starting in October 2018 and in March 2019.

\section{B. Tools and Materials}

Tools used:
a. Computer
b. printer
c. Android Application Studio
d. MySQL Database Server
e. XAMPP
f. Postman
g. MySQL Workbench
h. laravel

Materials used:

1. Data of finished products.

2. Data products selling

3. The sales data

4. Questionnaire data visitors

\section{Research procedure}

1. Needs analysis

Phase analysis phase is to identify and obtain data about the needs of what is required in the design and implementation of systems and design thinking to the next. According toPressman (2002), The analysis is a process of discovery, repair, and specifications. In this phase is to identify the data required for system development. Steps taken in analysis covering.

a) analysis of the technical specifications, the analysis of what are the capabilities required by the system,

b) job analysis system, the analysis of the performance of which will be performed by the system being designed or constructed.

2. design Model

Architecture

The architectural design is an overview of the system design models to be created.

Flow (flowchart)

Groove design is the description of how those processes derived from user activity contained in the application system.

3. Implementation (Coding)

Implementation is the stage of translating the modules into the system design in the form of an application by using a particular programming language and incorporate them into a whole integrated system. The steps that must be done in the implementation is.

a) collect and select modules that will be translated to programming languages

b) determine the program needed to support programs that have been designed

c) translating procedures, subroutines and functions of modules into the programming language

d) unify procedures, subroutines and functions of the modules that have been made into the unity of the program.

4. Testing (testing)

Testing the application is executing on a program to find errors. Before the program is received by the user, then the program must be detached from the mistakes of implementation. Therefore, the application should be tested to find errors that might occur. Testing is done for each module and proceed with testing for all modules that have been strung together. For an evaluation of this system modeling stage testing. These evaluations are used to improve the system in accordance with the required conditions. Stages are related to testing that is.

1) The trial against the database, application and hardware (hardware) support. Conducted to determine the performance of the system that has been built next to the components associated with the system's performance.

2) The test application, tested the feasibility and ease of use of the application. Tested the potential things goes wrong implementation and testing of the system keamanaan applications.

Repair, if possible in terms of the application will be made on the implementation of the troubled recording, as well as from the database and hardware if there is an error, it look for a solution at this stage.

\section{System Design and Database}

\section{UML design}

The design follows the form of UML use case shown in Figure 9 


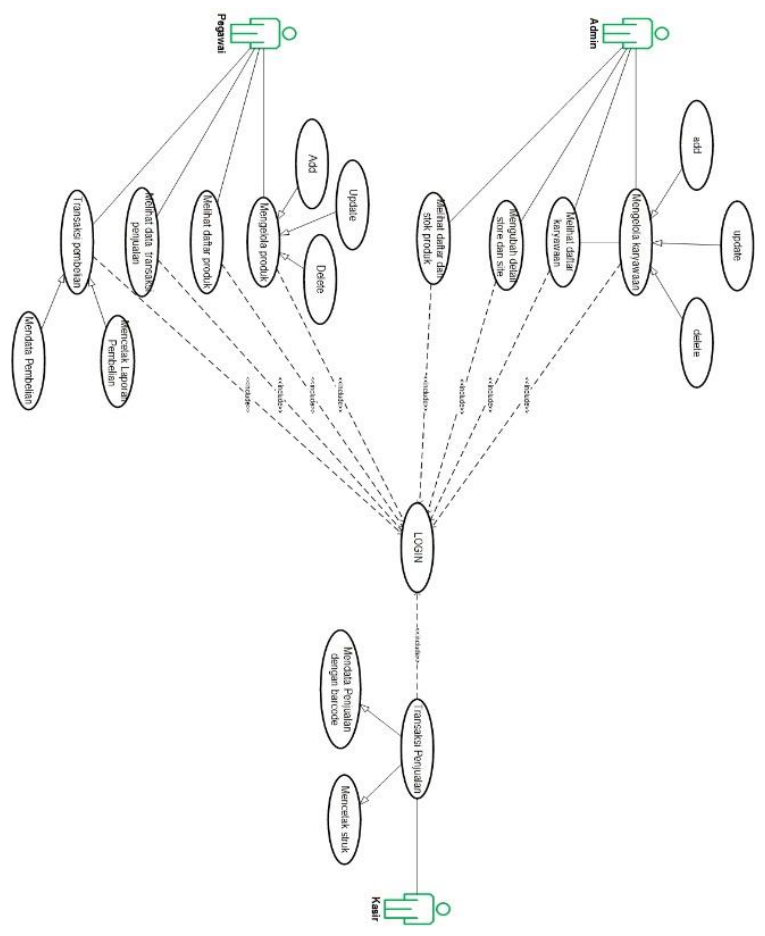

Figure 9. Usecase diagram

\section{RESULTS AND DISCUSSION}

\section{A. result}

Following This is a view of results and discussion of the application point of sale inventory management by using laravel. This display is made in such a way to facilitate business owners are able to understand and manage the income and expenditure of stocks and transactions on each sale.

1. Display results login form

Login Display is a display when it first entered on the application. Here's what the login form in Figure 11.

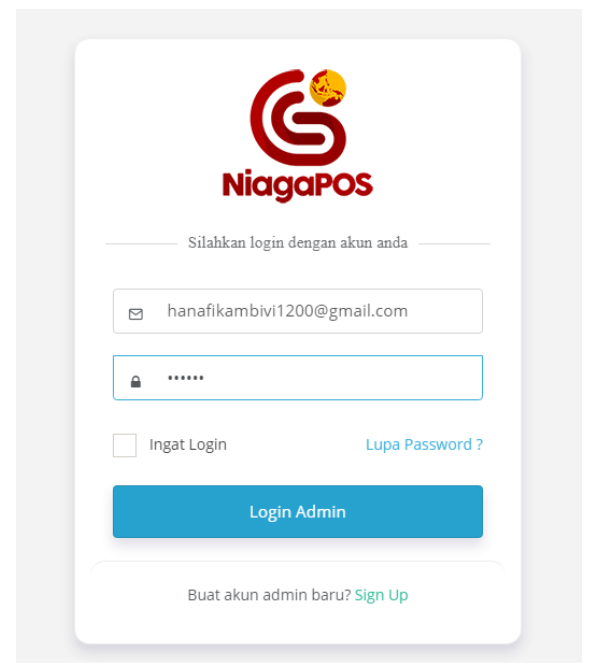

Picture 8, Login Form

2. Display results form homepage

The homepage has a data input such as input purchasing reports, sales reports, to the transaction data. Below the display form Home in figure 12.

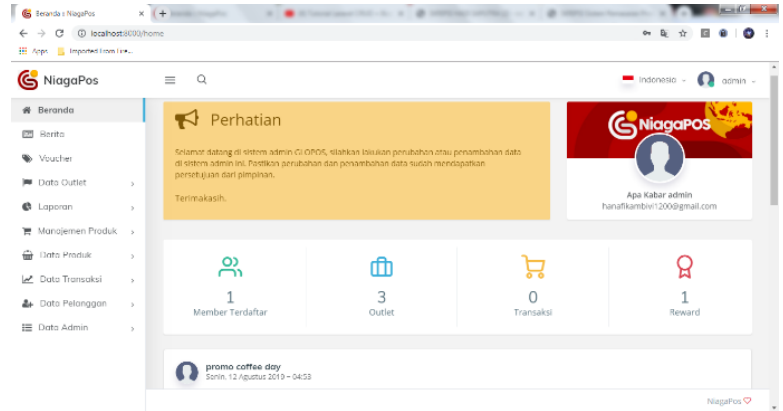

Picture 9, Home Form

3. Display sales results

Display sales results is a display that can also add sales data. In this form also in complete several actions to edit and delete, and view details on sales data. Below the display form Sales in figure 13.

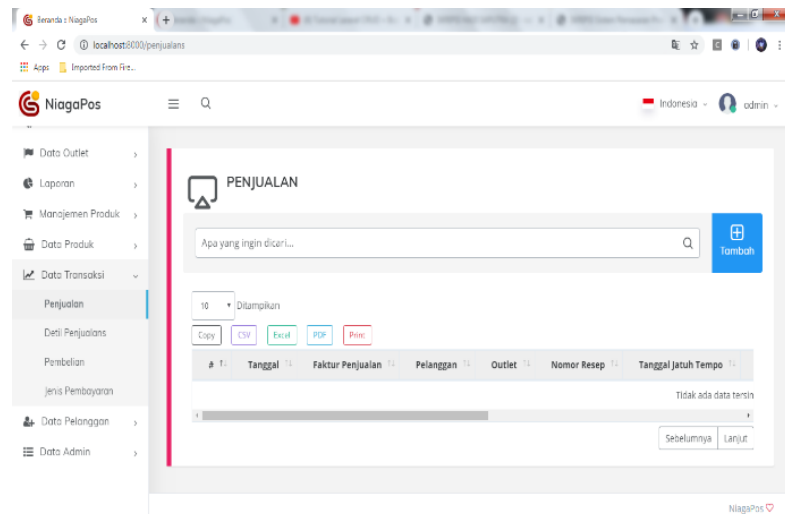

Picture 10, Sales Form

4. Display sales reports results

On the results of this view, we can see the sales transaction reports with the equipped charts is a benchmark to determine the results of previous sales. In the graph can also view daily sales results hinggu per month with the overall results. Below the display form Sales Report in Figure 14.

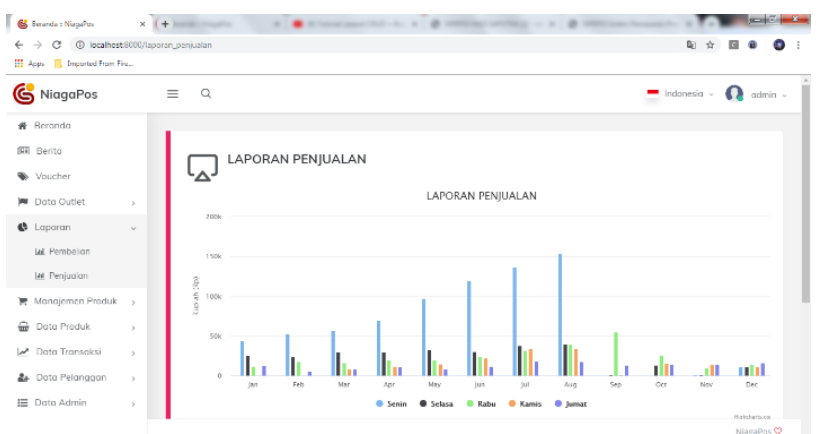

Picture 11, Form Sales Report

5. Views Purchased

Display the results of purchase displays several forms that can that can increase purchasing data, in this form are also available some action to edit, delete, and detail data and in this form can display all purchasing data that has been previously input. Below the display form Purchases at 15 images. 


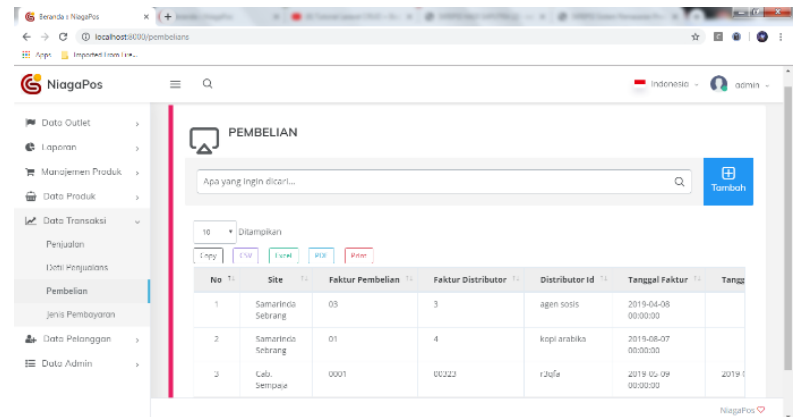

Picture 12, Purchase Form

6. Display result of input purchases

This display is an added detail on input purchases it will also include multiple input the invoice, the invoice Distributor, Distributor Id, invoice date, VAT, Discounts, and total purchase. Below the display form in Figure 16 Input Purchase.

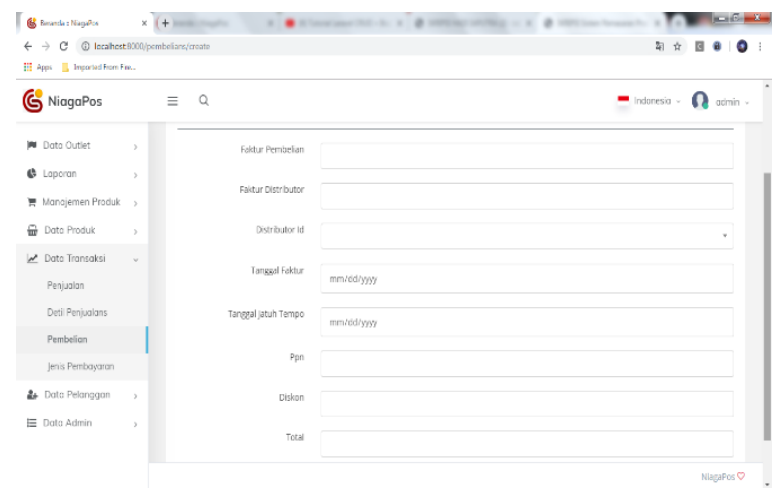

Picture 13, Input Form Purchase

7. See the report of purchase

On the results of this view, we can see the purchase transaction reports with the equipped charts is a benchmark to determine the results of the previous stock purchase. In the graph can also see sales results daily, weekly, monthly with the overall results, and also be able to see details of your purchase in the table below. Below the display form Purchase Report on picture 17.

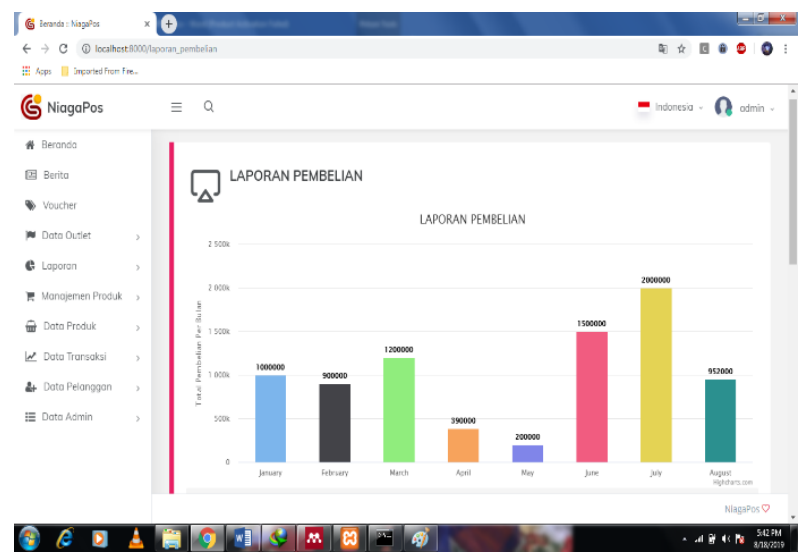

Picture 14, PembelianKesimpulan Report Form and Suggestions

\section{CONCLUSIONS AND RECOMMENDATIONS}

\section{A. Conclusion}

Based on the results of the inventory management application development point of sale using laravel was concluded as follows:
1. With the computerized system is expected to assist in preparing reports sales and inventory to be more controlled.

2. This application has to be used to determine the entry and exit of stock items.

3. Applications can display a report on every purchase.

\section{B. Suggestion}

To complete the inventory management application web-based Point of Sale is to be used better, it is necessary to some further development of this application, namely the presence of:

1. The application system can still be developed along with the development of user requirements specifications, particularly in terms of it's good to see made more attractive appearance.

2. This application in the allocation to the admin at the cashier in order to determine the input and output inventory.

3. Users must really understand the input data. 


\section{REFERENCES}

[1] Ading, R. (2013). Evaluation Application Design Lecturer By Student (EDOM) Based Android (Case Study in Akbid Bhakti Husada). School of Information Management and Computer.

[2] Cahyana, NH, Yuwono, B., \& Asmoro, LM (2012). Development of Information Systems Web-Based Inventory In Pt. Supreme Faithful Son. SemnasIf, 9 (semnasIF), 252-258.

[3] Dalgleish, T., Williams, JMG., Golden, A.-MJ, Perkins, N., Barrett, LF, Barnard, PJ, ... Watkins, E. (2007). making the application of point of sale on the cv. wacky media. Journal of Experimental Psychology: General, 136 (1), 23-42.

[4] Dharwiyanti, S., \& Wahono, SR (2003). Introduction to the Unified Modeling Language (UML). IlmuKomputer.Com, 1-13. https://doi.org/10.1016/j.jcrs.2009.09.016

[5] Gaffar, H. (2013). I introductory chapter 1.1. background. Hasanuddin University, 1-6. https://doi.org/10.1016/00028223(93)91952-M

[6] Hartono, J. (2005). Analysis and Information Systems. Yogyakarta: Andi.

[7] Herman, HT, Rostianingsih, S., Setiawan, A., Study, P., Informatics, T., Industry, FT, ... Surabaya, JS (2016). Making the Point of Sales Application for Eating Kitchen Rinjani. Infra, 4, 6.

[8] J, M, S, M., \& Yan, Z. (2009). RESTful Web Services: A Solution for Distributed Data Integration. International Conference on Computational Intelligence and Software Engineering, 6, 1-4.

[9] Pressman, RSP. (2002). Software Engineering Practitioner Approach (BOOK ONE). Yogyakarta.

[10] Rohman, A. (2014). Know Framework "laravel" (Best PHP Frameworks For 2014). Science Information Technology.

[11] Surya, L., Salim, P., \& Davin, J. (nd). Point of Sales System Application Web Based On Pt. Digital System Technology.

[12] Tanaem, PF (2016). RESTful Web Service For Recording System, 2 (April), 2443-2229.

[13] Utami. (2015). web-based sales information system. Technology and Information Science Journal, 40, 69-73.

[14] Wahyudi, IKAB, Son, IG. AW, \& Datya, AI (2017). Applications Sales Point of Sale (Pos) On Cooperatives Bina Kasih Sejahtera With First In First Out method (Fifo). Journal of Information and Computer Technology, 3 (2), 150-158. Retrieved from https://jurnal.undhirabali.ac.id/index.php/jutik/article/view/292

[15] Yulianty. (2010). "Application Point Of Sale at Retail Company (case study: Company Artha Jaya, Banjarnegara). Health Care, 313. https://doi.org/10.1163/15718085-12341263 